\title{
Formation evaluation challenges in Pliocene gas-bearing reservoirs from the Romanian Western Black Sea shelf
}

\author{
Bogdan Mihai Niculescu*, and Gina Andrei \\ University of Bucharest, Faculty of Geology and Geophysics, Department of Geophysics, \\ Bucharest, Romania
}

\begin{abstract}
This paper addresses some formation evaluation challenges and petrophysical particularities regarding two gas fields of Early Pliocene age, belonging to the biogenic hydrocarbon system of Western Black Sea Basin - Romanian continental shelf. Although these structures are located at the same depth and only $15 \mathrm{~km}$ apart, the wells that intercepted the sands and silts gas-bearing reservoirs indicate an important lateral facies variation and different reservoir qualities. We analyzed and interpreted data from exploration and appraisal wells that targeted these reservoirs, showing that: (1) there is a limited radioactivity contrast between the reservoir and nonreservoir intervals, so a clay volume determination based solely on the gamma ray log is not practical; (2) the reservoirs are characterized by high capillary-bound water contents, leading sometimes to abnormally low resistivity readings; (3) an additional resistivity suppression might be caused by the limited vertical resolution of the electrical logging tools, in the presence of thinly laminated sand - shale intervals; (4) the identification of gas-water contacts based exclusively on pressure gradients may be inaccurate and should be checked against the results of conventional geophysical logs interpretation and of nuclear magnetic resonance logs, for delineating the intervals with bound water or with movable fluids.
\end{abstract}

Keywords: biogenic gas, Black Sea, formation evaluation, Pliocene, well logging

\section{Introduction}

For oil and gas exploration wells, formation evaluation consists of the analysis and interpretation of geophysical well logging data and other types of subsurface information (e.g. well testing, formation testing and coring) in order to ascertain if commercially producible hydrocarbons are present and to determine the best means for their recovery. The key properties of reservoir rocks derived through formation evaluation (lithology, porosity, clay content, water and hydrocarbon saturations, hydrocarbons type, permeability, positions

\footnotetext{
* Corresponding author: bogdan.niculescu@gg.unibuc.ro
} 
of initial fluid contacts, petrophysical cut-offs) are used in further exploration, field development and resource estimates.

This paper addresses some of the formation evaluation challenges and petrophysical particularities regarding two gas fields (conventionally named Field A and Field B) of Early Pliocene (Dacian) age, belonging to the biogenic hydrocarbon system of Western Black Sea Basin - Romanian continental shelf. The geology, tectonics, evolution, hydrocarbon systems and hydrocarbon potential of this region have been studied and presented, among other authors, by Ionescu et al. [1], Dinu et al. [2], Moroşanu [3, 4] and Georgiev [5]. The gas discoveries are situated to the east of Constanţa harbour, in a shallow water $(45-125 \mathrm{~m}$ depth) exploration block which overlies the Tertiary-filled Histria Depression. They were identified and imaged using 2D and 3D seismic reflection surveys, started in 1992 and carried out until recent years. Although these dome structures are located at the same depth and only $15 \mathrm{~km}$ apart, in similar four-way dip closures, the exploration and appraisal wells that intercepted the sands and silts gas-bearing reservoirs show an important lateral facies variation between the two structures and clearly different reservoir qualities. Such variability cannot be detected on the seismic sections (both structures have quasi-identical reflection signatures), but is evident from the openhole geophysical logs responses and the drill cores taken from the reservoir intervals. In the same time, the reservoir intervals for both fields are characterized by a vertical variability of the grain size, with sandy units overlying silty units, in a more or less gradual transition.

The petrophysical analysis of the gas fields taken into consideration has presented a number of challenges since their discovery. The sands are highly unconsolidated, fine to very fine grained, trending to silts, with abundant small pores that can trap large volumes of bound water. Consequently, the main challenges have been in the determination of realistic water and gas saturations, clay content and porosity, gas-water contacts and the net contributing reservoirs. We show and discuss particular issues related to the log interpretation and formation evaluation for these fields, together with the implications of depositional facies variability upon the resource estimates.

\section{Geological settings}

The Western Black Sea Basin is an important hydrocarbon-bearing region in SE Europe. Up to now, on the Romanian continental shelf, the main area of interest from the standpoint of hydrocarbons potential is the Histria Depression (Fig. 1), a post-tectonic cover superimposed over the North Dobrogea Orogen, formed by extension beginning with Aptian - Albian and until Eocene, then followed by subsidence $[2,4]$. This sedimentary basin gradually expands and deepens towards SE and merges with Western Black Sea Basin floor [5]. In this region, oil-bearing reservoirs have been identified in Albian, Late Cretaceous (Turonian, Coniacian, Santonian), Eocene and Oligocene formations, whereas gas shows or commercial gas accumulations are located in Cretaceous, Eocene and especially Late Miocene - Early Pliocene (Pontian and Dacian) formations $[1,4,5]$. In the pre-Oligocene and Oligocene formations, the traps are either tectonic (anticlines, faulted anticlines) or stratigraphic (pinchouts, drape anticlines). In the post-Oligocene formations, the traps are of stratigraphic type, such as depositional fans or anticlines of differential setting, extended over wide areas and sometimes affected by gravity faults and growth faults.

According to Moroşanu [4], four thermogenic petroleum systems and one biogenic gas system are present in the Romanian continental shelf area of the Western Black Sea. The biogenic system comprises the Midia, Ovidiu, Cobălcescu, Ana, Doina and Domino gas fields. 


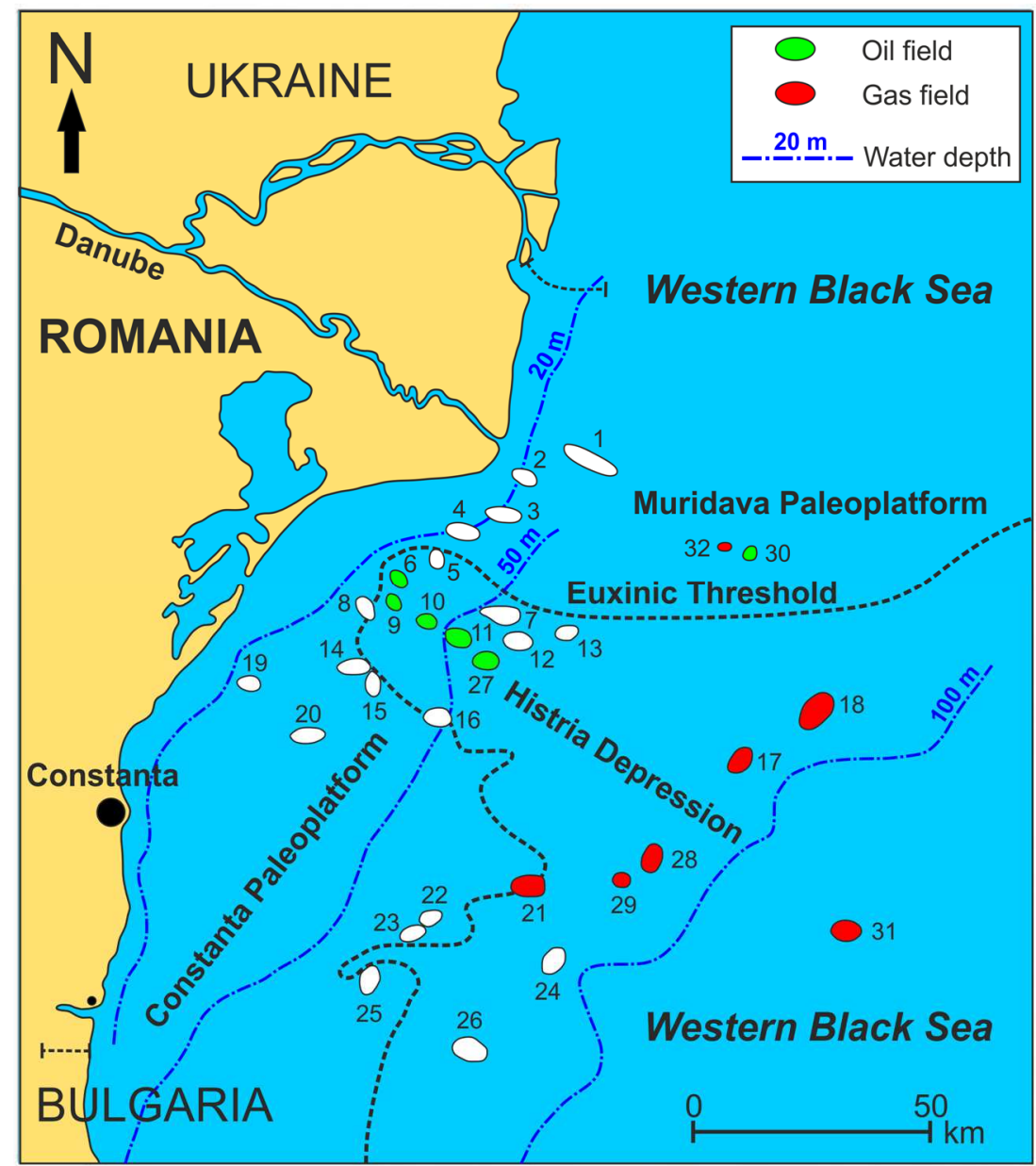

Fig. 1. Location map of the Romanian Black Sea shelf showing the main plays and leads. $1-\mathrm{Sf}$. Gheorghe, 2 - Pelican, 3 - Sacalin, 4 - Sturion, 5 - Egreta, 6 - Portiţa, 7 - Heracleea, 8 - Venus, 9 Sinoe, 10 - Lebăda-W, 11 - Lebăda-E, 12 - Minerva, 13 - Albatros, 14 - Iris, 15 - Lotus, 16 Tomis, 17 - Ovidiu, 18 - Cobălcescu, 19 - Vadu, 20 - Corbu, 21 - Midia, 22 - Meduza, 23 - Neptun, 24 - Neptun-E, 25 - Delfin, 26 - Jupiter, 27 - Pescăruş, 28 - Doina, 29 - Ana, 30 - Muridava (Olimpyska), 31 - Domino, 32 - Eugenia (adapted from [4]).

Gas is reservoired in Pontian - Dacian sands; the source rocks are considered to be the Middle-Late Miocene (Sarmatian or Early Pontian) pelitic deposits and the seals can be represented by all pelitic Pliocene intervals. The traps for the biogenic gas system include drape anticlines, roll-over anticlines, monocline beds affected by listric faults and stratigraphic traps (pinch-outs, depositional fans).

The gas discoveries considered in this study are hosted in four-way closure dome structures by Dacian sands, the reservoirs tops being located at $1094-1120 \mathrm{~m}$ true vertical depth subsea. The sands are immature, poorly consolidated (little or no authigenic or diagenetic cements), fine to very fine grained, muddy to silty, sometimes thinly bedded. The overall depositional environment is most likely shallow marine, in water depths between 25 and $100 \mathrm{~m}$ (lower shoreface to upper offshore regime), with frequent sediment influx being provided from a delta system situated approximately to the NW. The wells drilled on these structures reveal a vertical variability of the reservoir intervals grain size, allowing their separation into a "Sand" upper facies (good reservoir quality, fine sands) of $15-28 \mathrm{~m}$ 
thickness and a "Silt" bottom facies (poor reservoir quality, silty sands, silts and muddy silts) of $14-47 \mathrm{~m}$ thickness. This vertical distinction is more clear in Field A (located towards SW in the exploration block taken into consideration) than in Field B (located towards NE in the exploration block), where the reservoir quality is lower, with higher silt and clay contents and fewer thick sand intervals.

\section{Data and methodology}

We analyzed and interpreted complex data made available by the Romanian oil and gas industry from several exploration and appraisal wells that targeted the Dacian gas-bearing reservoirs. All the wells were drilled with a water-based $\mathrm{KCl}$ mud (mud density: 9.6 to 10 $\mathrm{lb} /$ gal, equivalent to $1.15-1.20 \mathrm{~g} / \mathrm{cm}^{3}$ ) and generally show good hole conditions. The data consisted of wireline geophysical logs, formation tester pressure measurements and fluid samples (RFT - Repeat Formation Tester and MDT - Modular Formation Dynamics Tester), conventional and special laboratory petrophysical measurements on cores and $\mathrm{X}$-ray diffraction (XRD) analyses.

A total of 105 successful pressure measurements were carried out with wireline formation testers in the wells from Field A and Field B. Reservoir pressures range from 1686 to 1719 psia $(116.2$ - 118.5 bar) in Field A and from 1600 to 1716 psia $(110.3-118.3$ bar $)$ in Field $\mathrm{B}$. The gas samples collected during wireline testing operations in three wells drilled in these fields show it has very high methane content $(99.7-99.9 \%)$ and does not contain $\mathrm{H}_{2} \mathrm{~S}$. At the reservoirs pressure and temperature $\left(38-40{ }^{\circ} \mathrm{C}\right.$, measured in the wireline logging and formation tester runs), gas density is approximately $0.08 \mathrm{~g} / \mathrm{cm}^{3}$.

XRD analyses performed on 16 core samples extracted from the "Sand" reservoir facies of Field A show a total clay content ranging from $13 \%$ to $53 \%$ by weight ( $29 \%$ on average). The clays present are predominantly illite + mica, mixed-layer illite/smectite and chlorite, with only subordinate kaolinite observed. The additional electrical conductivity associated with the presence of clay minerals in the reservoirs requires a "shaly sands"-type interpretation of the geophysical well logs, to compute realistic water and gas saturations.

The wireline well logging suites recorded over the 8.5 inch diameter final sections of the wells included total gamma ray, apparent resistivity (Dual Laterolog, Laterolog Array and focused microresistivity tools), neutron porosity, litho-density (bulk density and photoelectric factor) and compressional sonic transit time. For some of the recently drilled wells, electrical imaging (FMI - Fullbore Formation Microimager) and nuclear magnetic resonance (CMR - Combinable Magnetic Resonance Tool) logs were also available. Figures 2 and 3 show the geophysical well logs recorded in two exploration wells from Field A and Field B, over the main reservoir intervals (Fig. 2: track 1 - measured depth (MD) and borehole's temperature; track 2 - true vertical depth subsea (TVDSS); track 3 -zonation of the reservoir intervals; track 4 - total gamma ray, caliper and bit size; track 5 - apparent resistivities (Laterolog Array curves and flushed zone microresistivity); track 6 - neutron porosity, bulk density and photoelectric factor curves overlay on a limestone compatible scale; track 7 - neutron porosity and bulk density curves overlay on a sandstone compatible scale; track 8 - compressional sonic transit time (slowness or reciprocal velocity); track $9-$ nuclear magnetic resonance (CMR) $T_{2}$ transverse relaxation time distribution; track $10-$ formation tester pressure readings).

In the wells drilled in Field A (Fig. 2), the main reservoir unit consists of a $26-27 \mathrm{~m}$ thick upper interval with significant gas crossover on the density-neutron overlay, deep resistivities reaching $170-384 \Omega \cdot \mathrm{m}$, free fluid indication on the CMR's $T_{2}$ distribution (large $T_{2}$ values), and a strong compressional sonic $\Delta t$ response of $170-200 \mu \mathrm{s} / \mathrm{ft}$ (compared to the $130-140 \mu \mathrm{s} / \mathrm{ft}$ slowness recorded in the adjacent non-reservoir intervals), indicating gasbearing formations. 


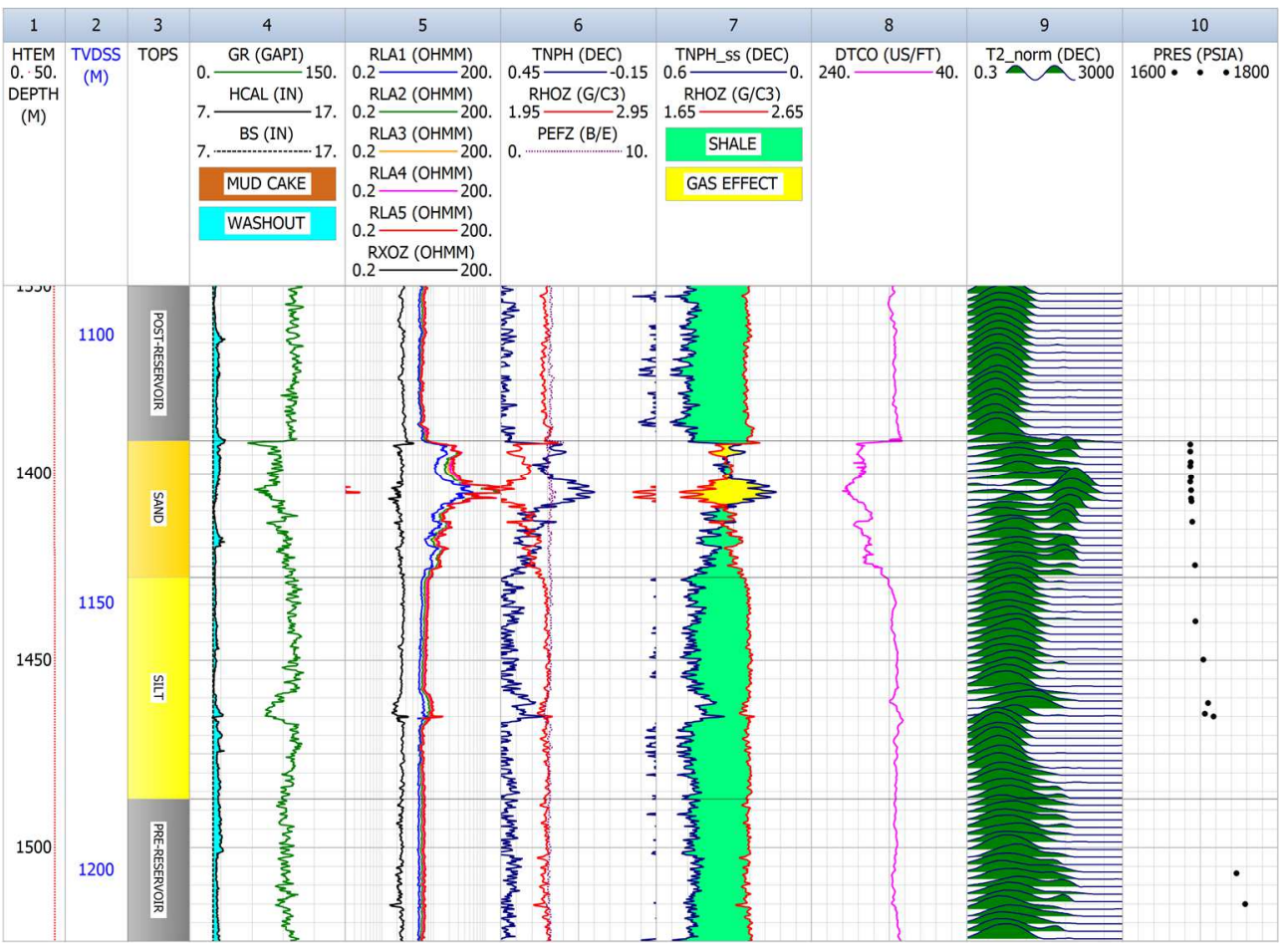

Fig. 2. Wireline geophysical well logs recorded in an exploration well from Field A.

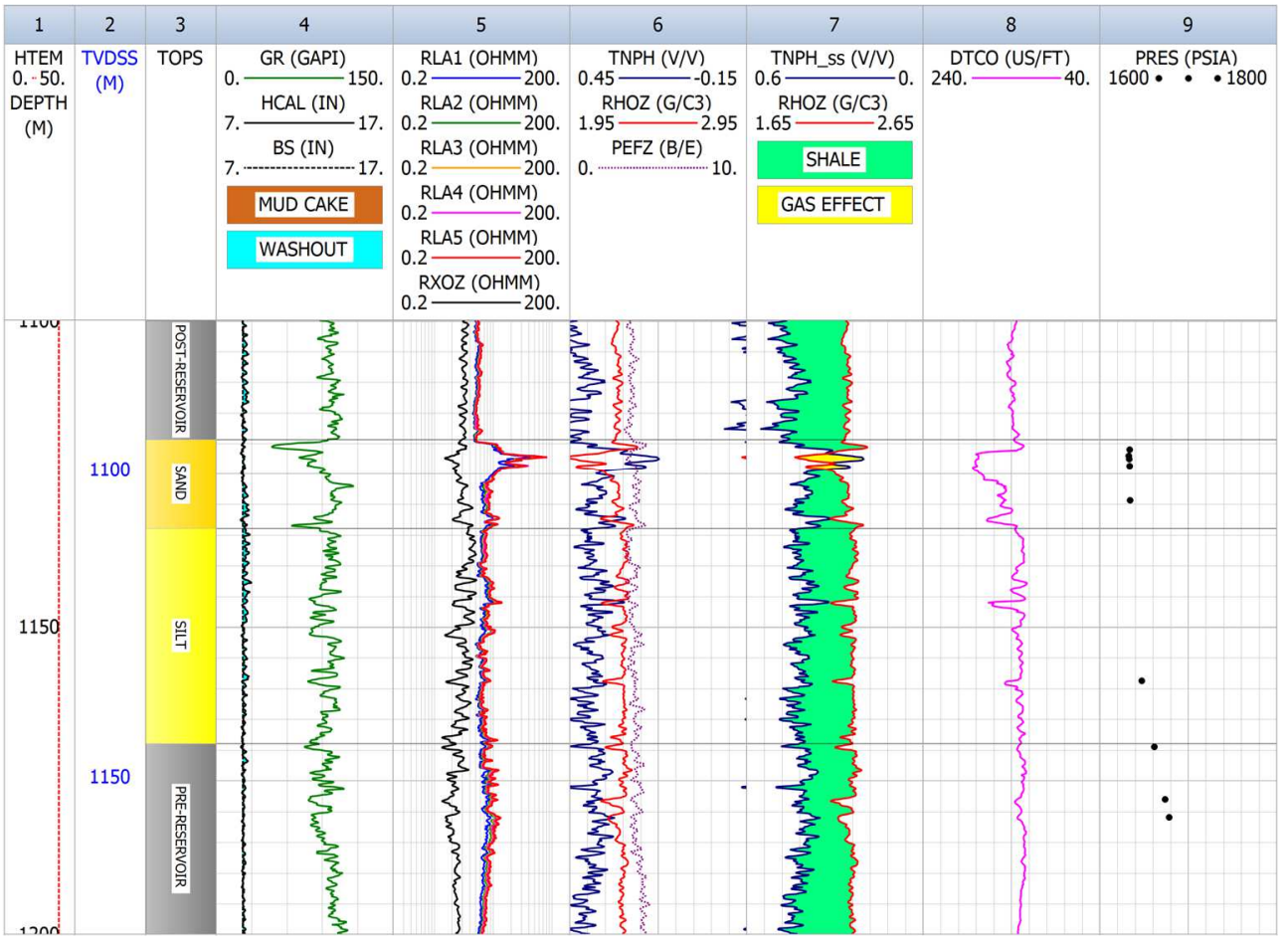

Fig. 3. Wireline geophysical well logs recorded in an exploration well from Field B. 
Total gamma ray logs $(G R)$ recorded in the wells shows an unusually low contrast between reservoir and non-reservoir intervals. The increased radioactivity of the reservoir rocks may be explained by a higher adsorption of radionuclides in the very fine sands and silts and, also, by the presence of potassium-bearing mica. The lower ("Silt") part of the reservoir unit, 38 $41 \mathrm{~m}$ thick, displays no density-neutron crossover, slight and local resistivity and $T_{2}$ time increases (little free fluid), possibly indicating small gas saturations at particular depth levels. Generally, the $G R \log$ subtle trends observed along the reservoir intervals are of coarseningupward type (prograding sequences).

In the wells drilled in Field B (Fig. 3) the "Sand" main reservoir unit, 15 - $28 \mathrm{~m}$ thick, appears with the same general well $\log$ signature as in Field A, i.e. with a suppressed $G R$ response, few and thinner intervals with density-neutron gas crossover and much lower deep resistivities (maximum readings of $16-82 \Omega \cdot \mathrm{m}$ ), but again with a distinct sonic response suggesting gas-bearing formations $(\Delta t$ reaching $180-190 \mu \mathrm{s} / \mathrm{ft}$ in the main reservoir compared to $125-140 \mu \mathrm{s} / \mathrm{ft}$ in the non-reservoir intervals).

The wireline logging data processing and interpretation consisted of:

1) Clay volume $\left(V_{\text {clay }}\right)$ estimation by using a combination of gamma ray and density-neutron clay indicators. A linear clay volume estimated from the $G R \log \left(V_{\text {clay, GR }}\right)$ was calibrated against a clay volume estimated from the density-neutron crossplot $\left(V_{\text {clay,DN }}\right)$ in order to obtain $V_{\text {clay, GR }} \approx V_{\text {clay }, D N} \approx 1(100 \%)$ at the depth levels with good hole conditions and a maximum and consistent separation between the neutron and density curves $\left(\phi_{N}-\phi_{D}\right)$ on a sandstone compatible porosity scale. The corresponding expressions are

$$
\begin{gathered}
V_{\text {clay }, G R}=\left(G R-G R_{\text {clean }}\right) /\left(G R_{\text {clay }}-G R_{\text {clean }}\right) \\
V_{\text {clay }, N D}=\left(\phi_{N}-\phi_{D}\right) /\left(\phi_{\text {Nclay }}-\phi_{\text {Dclay }}\right) \\
\phi_{D}=\left(\delta_{m a}-\delta\right) /\left(\delta_{m a}-\delta_{f}\right) \\
\phi_{\text {Dclay }}=\left(\delta_{m a}-\delta_{\text {clay }}\right) /\left(\delta_{m a}-\delta_{f}\right)
\end{gathered}
$$

where: $G R$ - measured gamma ray radioactivity (API), $G R_{\text {clean }}$ - gamma ray radioactivity of clean reservoirs intervals (API), $G R_{\text {clay }}$ - gamma ray radioactivity of clays (API), $\phi_{N}-$ measured neutron porosity, corrected for sandstone lithology $(\mathrm{V} / \mathrm{V}), \phi_{\text {Nclay }}-$ clay neutron porosity $(\mathrm{V} / \mathrm{V}), \phi_{D}$ - density porosity computed for a sandstone matrix $(\mathrm{V} / \mathrm{V}), \phi_{\text {Dclay }}-$ clay density porosity $(\mathrm{V} / \mathrm{V}), \delta$ - measured bulk density $\left(\mathrm{g} / \mathrm{cm}^{3}\right), \delta_{m a}-$ sandstone matrix density $\left(\mathrm{g} / \mathrm{cm}^{3}\right), \delta_{\text {clay }}$ - clay density $\left(\mathrm{g} / \mathrm{cm}^{3}\right), \delta_{f}$ - pore fluid (mud filtrate) density $\left(\mathrm{g} / \mathrm{cm}^{3}\right)$. The $V_{\text {clay, GR }}$ calibration with respect to the reference $V_{\text {clay,DN }}$ can be achieved via an adequate selection of the clean and clay $G R$ responses. The density-neutron combination has the advantage of not depending on formations radioactivity, but $V_{\text {clay, } D N}$ from Eq. (2) will not work in gas-bearing intervals. Once calibrated against $V_{\text {clay,DN }}$ on clay/shale or waterbearing intervals, $V_{\text {clay, GR }}$ can be used as a valid clay volume estimator for the entire interpreted intervals, because it is not affected by light hydrocarbon (gas) effects.

2) Effective porosity $(\phi)$ estimation by using a density-neutron crossplot porosity model appropriate for shaly sands. The matrix (grain) densities $\delta_{m a}$ of $2.67-2.69 \mathrm{~g} / \mathrm{cm}^{3}$ used in the calculations were obtained from measurements on core plugs. The clay parameters were statistically selected from the logs, resulting neutron porosities $\phi_{\text {Nclay }}=0.45-0.50$ and densities $\delta_{\text {clay }}=2.25-2.26 \mathrm{~g} / \mathrm{cm}^{3}$.

3) Estimation of formation water resistivity $\left(\rho_{w}\right)$ by using effective porosity vs. true resistivity Pickett crossplots [6], i.e. $\log (\phi)=f\left(\log \left(\rho_{t}\right)\right)$, and approximating $\rho_{t}$ with the deepest investigation apparent resistivity curves RLA5 (Fig. 4). For the wells of Field A we obtained $\rho_{w}=0.5-0.6 \Omega \cdot \mathrm{m}$ at formations temperature, corresponding to salinities of $6600-9100$ ppm equivalent $\mathrm{NaCl}$. 


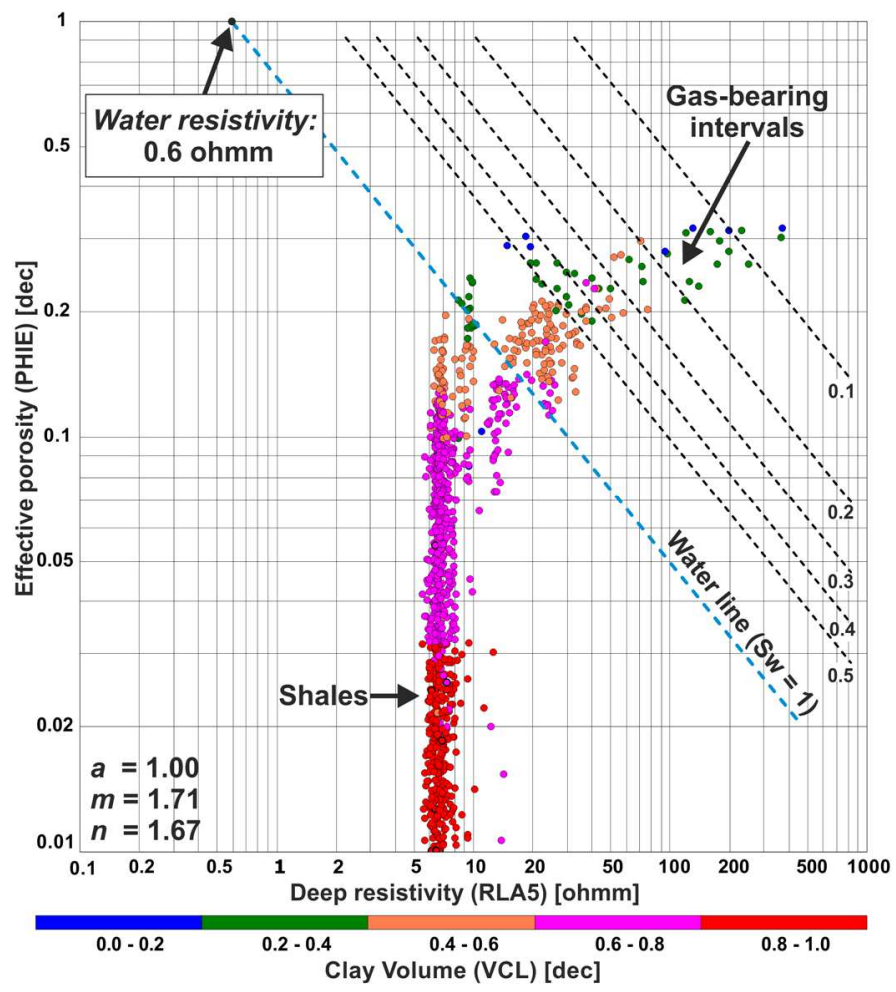

Fig. 4. Effective porosity (log-derived) vs. deep resistivity crossplot for an exploration well from Field A. The $S_{w}=1$ "water line" is defined as passing through the change of trend of the resistivity porosity data (shales vs. reservoir rocks). The very limited effective porosity variation range of the reservoir rocks does not allow a clear linear trend to be observed for the water-bearing levels.

For the wells of Field B we obtained $\rho_{w}=0.9-1.2 \Omega \cdot \mathrm{m}$ at formations temperature, corresponding to salinities of $3400-4700 \mathrm{ppm}$ equivalent $\mathrm{NaCl}$. The relatively fresh, low salinity, formation waters suggest that the clay content has a significant effect upon the bulk rock resistivities, by providing an additional conduction path for the electrical current.

4) Estimation of water saturations $\left(S_{w}, S_{x o}\right)$ and total, movable and residual hydrocarbon saturations $\left(S_{h}, S_{h m}, S_{h r}\right)$ in the reservoir intervals by using a shaly sands saturation model [7], in the effective porosity system. Clay resistivities were statistically selected from the $\operatorname{logs}\left(\rho_{\text {clay }}=5.2-8.5 \Omega \cdot \mathrm{m}\right)$ and the water saturations were computed using Archie parameters [8] measured on core plugs, at a confining pressure representative for reservoir conditions. For Field A the average values of these parameters were $a=1.0$ (the socalled tortuosity factor), $m=1.71$ (cementation exponent), $n=1.67$ (saturation exponent) and for Field B the average parameters were $a=1.0, m=1.54, n=1.33$.

5) Processing the CMR $T_{2}$ transverse relaxation time distribution, in order to compute claybound water, capillary-bound water and free fluid volumes ( $T_{2}$ cutoffs of $3 \mathrm{~ms}$ and $33 \mathrm{~ms}$, typical for sands / sandstones, were used to separate the three types of pore fluids), as well as a CMR-derived water saturation.

6) Linear regression analysis on the good quality formation pressure data, in order to derive the pressure gradients $(\Delta p / \Delta H$, where $p$ - measured formations pressure, $H$-true vertical depth), the formation fluids in-situ densities and to identify the probable gas-water contacts (GWC). 
7) Establishing petrophysical cutoffs, in order to delineate net reservoir and net pay intervals. The cutoffs were obtained by analyzing the relationships between the permeability $(k)$ measured on core plugs at appropriate confining pressure and the logderived $\phi$ and $S_{w}$. For $k=0.1 \mathrm{mD}$ as a minimum acceptable limit appropriate for gas, we obtained $\phi$ cutoff $\approx 8-11 \%$ and $S_{w}$ cutoff $\approx 70 \%$, for both Field A and Field B.

\section{Results and discussion}

Figure 5 illustrates an example of petrophysical interpretation results for the wireline logs recorded in the exploration well from Field A (Fig. 2): track 1 - measured depth (MD) and borehole's temperature; track 2 - true vertical depth subsea (TVDSS); track 3 -zonation of the reservoir intervals; track 4 - total gamma ray, caliper and bit size; track 5 - water saturations in the uninvaded and flushed zones $\left(S_{w}, S_{x o}\right)$; track 6 - bulk volumes of formation water, movable and residual (immobile) gas; track 7 - lithology analysis (volume fractions of clay, silt, sand and effective porosity); track 8 - oriented borehole electrical image (light tones: high resistivity, dark tones: low resistivity); track 9 - processed nuclear magnetic resonance (CMR) data showing the volumes of clay-bound water, capillary-bound water and free fluids; track 10 - computed pressure gradients and formation fluids densities; tracks 11 and 12 - delineation of net reservoir and net pay intervals using the cutoffs $\phi=10 \%$ and $S_{w}$ $=70 \%$, corresponding to $k=0.1 \mathrm{mD}$.

Two distinct gas-bearing reservoirs resulted from interpretation in the "Sand" and "Silt" units. By applying the $\phi$ and $S_{w}$ cutoffs, these reservoirs are located on the $1391.6-1425.5$ m MD (1119.8 - 1143.6 m TVDSS) and, respectively, 1458.6 - $1466.7 \mathrm{~m} \mathrm{MD} \mathrm{(1166.7} \mathrm{-}$ $1172.3 \mathrm{~m}$ TVDSS) intervals. The main, $23.8 \mathrm{~m}$ thick, upper reservoir has an average $\phi$ of $15.6 \%$, locally reaching $31.9 \%$, the minimum computed $S_{w}$ being $4.4 \%$ (a maximum gas saturation of $95.6 \%$ ). The $5.6 \mathrm{~m}$ thick secondary reservoir has an average $\phi$ of $14.8 \%$, locally reaching $24.2 \%$, and a minimum computed $S_{w}$ of $49.7 \%$.

As observed in Fig. 2 and Fig. 5, the maximum recorded resistivities and the corresponding maximum computed gas saturation and gas volume do not occur at the top of the main "Sand" reservoir, but 13 to $15 \mathrm{~m}$ lower. The resistivity suppression in the upper part of the main reservoir, especially on the $1392-1404 \mathrm{~m} \mathrm{MD}$ interval, is due to a large amount of capillary-bound water (up to $14-15 \%$ volume) at the reservoir's top, as shown by the CMR results. This abnormal amount of water, which is irreducible (immobile), can be explained by the presence of a siltstone interval at the top of the generally coarser-grained "Sand" reservoir. Such siltstones typically have low resistivities but can produce clean (water-free) hydrocarbons.

Another significant cause of resistivity suppression comes from the thinly laminated nature of some reservoirs, especially in Field B (Fig. 3), as indicated by the drill cores photographs and descriptions. The interbedded thin and resistive sands/silts and conductive mudstones, with millimeter to decimeter bed thicknesses, cannot be properly resolved by the electrical logging tools and their resistivities are averaged. This leads to a severe underestimation of the thin reservoir beds true resistivities (maximum recorded resistivities in the main reservoir intervals of Field B are one order of magnitude smaller than the ones measured in Field A) and to computing unrealistically high water saturations and low gas saturations. In this regard, the minimum $S_{w}$ values obtained for the "Sand" interval in the wells of Field B range from $9.1 \%$ to $34.9 \%$, whereas in Field A they range from $4.4 \%$ to $8.2 \%$. One way of mitigating this problem would be to investigate the ability of modern tensor / 3D or azimuthal resistivity tools (such as Schlumberger's Rt Scanner or the ARI Azimuthal Resistivity Imager) to resolve the thinly laminated sand beds and determine more realistic true resistivities for water saturation determination. Another way would be a deconvolution processing of resistivity logs, in order to improve their vertical resolution. 


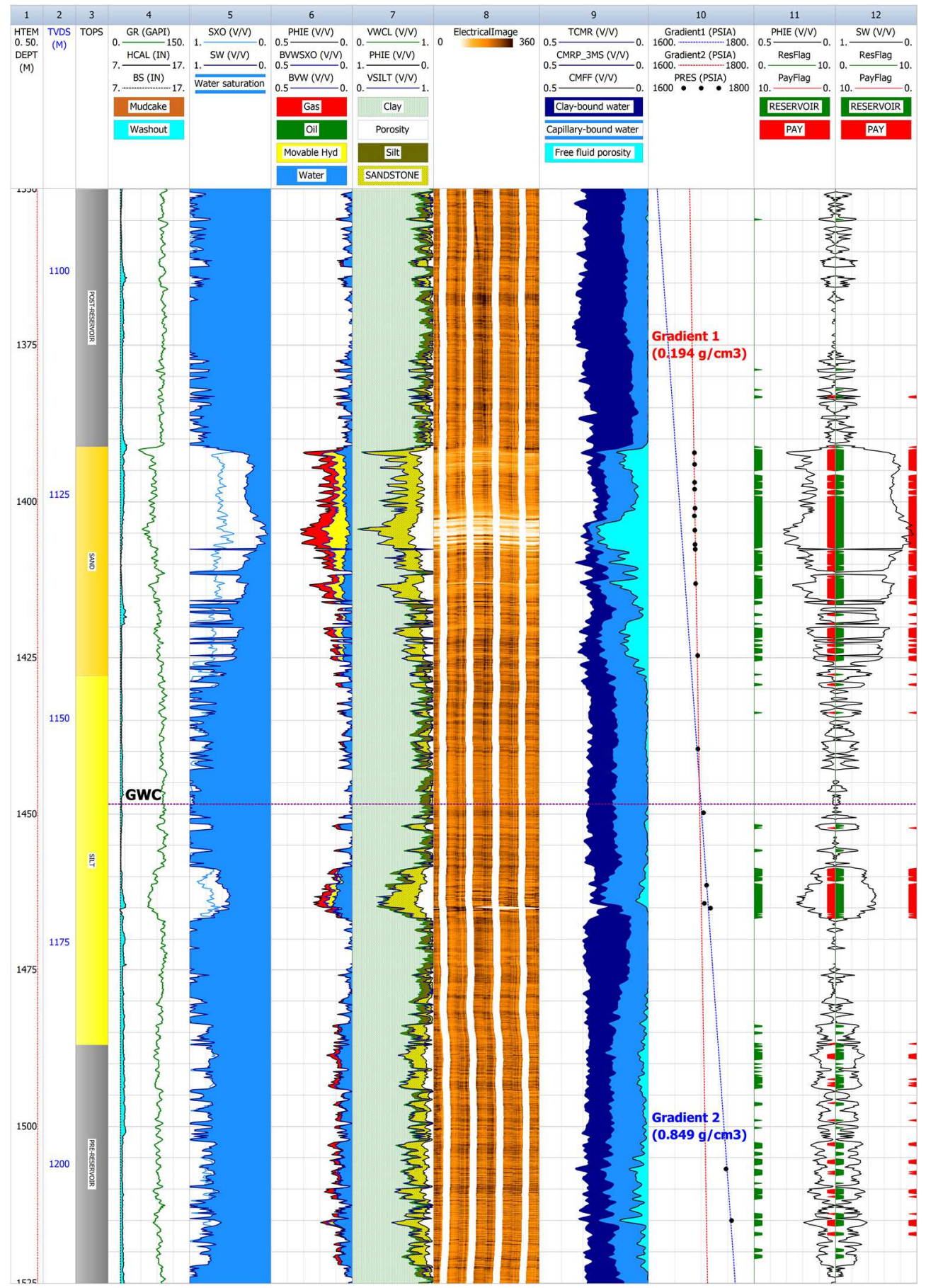

Fig. 5. Petrophysical interpretation of the wireline well logs recorded in an exploration well from Field A. The GWC level marks the gas-water contact suggested by the intersection of the pressure gradients at $1448.4 \mathrm{~m} \mathrm{MD} \mathrm{(1159.6} \mathrm{m} \mathrm{TVDSS).} \mathrm{This} \mathrm{apparent} \mathrm{GWC} \mathrm{is} \mathrm{located} \mathrm{between} \mathrm{two} \mathrm{gas-}$ bearing reservoirs resulted from the interpretation, at a depth where the processed nuclear magnetic resonance data show no indication of free fluids, but only bound (immobile) water. 
The pressure gradients analysis in Fig. 5 indicates the presence of two fluids and corresponds to the hydrocarbon pressure gradient and the hydrostatic pressure gradient. The densities of these fluids, computed from the pressure gradients, are $\delta_{f 1}=0.194 \mathrm{~g} / \mathrm{cm}^{3}$ (gas) and $\delta_{f 2}=0.849 \mathrm{~g} / \mathrm{cm}^{3}$ (water), higher and, respectively, lower than the true densities of gas and formation water in the studied fields. For only one out of six analyzed wells a correct gas density $\left(0.083 \mathrm{~g} / \mathrm{cm}^{3}\right)$ was obtained from the pressure gradients, in the other cases the resulted gas densities were too high $\left(>0.1 \mathrm{~g} / \mathrm{cm}^{3}\right)$. Formation water estimated densities were too low $\left(<1 \mathrm{~g} / \mathrm{cm}^{3}\right)$ for the wells in Field A, but realistic for the wells in Field B, ranging from 1.014 to $1.038 \mathrm{~g} / \mathrm{cm}^{3}$. A possible cause for the differences between true and estimated fluid densities may consist in the formation testers not reading pressures corresponding to pure fluids, but to mixtures of gas and water or water and gas. In this case, the gas-water contact depth inferred solely from the pressure gradients intersection may be significantly inaccurate, leading to errors in the volumetric estimation of gas resources. This GWC uncertainty, which cannot be ruled out, could also manifest itself in the form of pressure gradients intersection being located at a depth level with no free fluids indications on the results of nuclear magnetic resonance $\log$, i.e. within an impermeable formation.

\section{Conclusions}

We analyzed complex borehole data (wireline geophysical well logs, formation pressures and fluid samples, petrophysical measurements on cores and X-ray diffraction measurements) available for several exploration and appraisal wells drilled on the Romanian continental shelf of the Black Sea, which targeted Early Pliocene (Dacian) gas-bearing reservoirs. The analysis revealed some particular challenges related to the petrophysical evaluation of these formations, such as the low $G R$ contrast of the reservoirs, the frequent suppression of resistivity logs readings and the uncertainty of gas-water contacts identification.

\section{References}

1. G. Ionescu, M. Sisman, R. Cataraiani, Source and reservoir rocks and trapping mechanism on the Romanian Black Sea shelf. In: C. Dinu and V. Mocanu (eds.), Geology and Tectonics of the Romanian Black Sea Shelf and its Hydrocarbon Potential, Bucharest Geoscience Forum, Special Volume 2, 67-83 (2002)

2. C. Dinu, H.K. Wong, D. Ţambrea, L. Maţenco, Stratigraphic and structural characteristics of the Romanian Black Sea shelf, Tectonophysics 410, 417- 435 (2005)

3. I. Moroşanu, Romanian Continental Plateau of the Black Sea: Tectonic-Sedimentary Evolution and Hydrocarbon Potential, Oscar Print Publishing House, Bucharest, Romania, 176 pp., ISBN 978-973-668-167-7 (2007)

4. I. Moroşanu, The hydrocarbon potential of the Romanian Black Sea continental plateau, Romanian Journal of Earth Sciences 86, 2, 91-109 (2012)

5. G. Georgiev, Geology and Hydrocarbon Systems in the Western Black Sea, Turkish Journal of Earth Sciences 21, 723-754 (2012)

6. G.R. Pickett, Pattern recognition as a means of formation evaluation, The Log Analyst 14, 4, 3-11 (1973)

7. A. Poupon, J. Leveaux, Evaluation of water saturation in shaly formations, The Log Analyst 12, 4, 3-8 (1971)

8. G.E. Archie, The electrical resistivity $\log$ as an aid in determining some reservoir characteristics, Transactions of the AIME 146, 1, 54-62 (1942) 